\title{
Application of Matrix-Assisted Laser Desorption/Ionization Time-of-Flight Mass Spectrometry for the Rapid Identification of Yeast Species From Polar Regions
}

\author{
Chenyang He, Jianju Feng, Jing Su, Tao Zhang* and Liyan Yu* \\ China Pharmaceutical Culture Collection, Institute of Medicinal Biotechnology, Chinese Academy of Medical Sciences and \\ Peking Union Medical College, Beijing, China
}

OPEN ACCESS

Edited by:

Praveen Rahi,

National Centre for Cell Science,

India

Reviewed by:

Luca Roscini,

University of Perugia, Italy

Satish Pote,

National Centre for Cell Science,

India

*Correspondence:

Tao Zhang

zhangt@cpcc.ac.cn

Liyan Yu

yly@cpcc.ac.cn

Specialty section:

This article was submitted to

Systems Microbiology,

a section of the journal

Frontiers in Microbiology

Received: 10 December 2021

Accepted: 02 February 2022

Published: 23 February 2022

Citation:

He C, Feng J, Su J, Zhang T and

Yu L (2022) Application of MatrixAssisted Laser Desorption/Ionization Time-of-Flight Mass Spectrometry for

the Rapid Identification of Yeast

Species From Polar Regions.

Front. Microbiol. 13:832893.

doi: 10.3389/fmicb.2022.832893
Protein profiling based on matrix-assisted laser desorption/ionization time-of-flight (MALDI-TOF) mass spectrometry (MS) has proved to be a powerful tool for yeast identification. However, it is rarely used in the identification of yeast isolates from polar regions, which may be due to the limited data available for the differentiation of polar yeast species. The present study constructed a supplementary database of MALDI-TOF MS, including 33 yeast species from the Arctic and Antarctica. These yeast species were used to assess the accuracy and practicality of MALDI-TOF MS-based identification compared to the ribosomal DNA [internal transcribed spacer (ITS) and large subunit (LSU) gene regions] sequencing identification. Their dendrogram based on main spectra profiles (MSPs) in the supplementary database was somewhat consistent with their phylogenetic tree. The accuracy of MALDI-TOF MS identification was also compared by the ethanolformic acid extraction method and the on-plate extraction method. In addition, peptide markers of some yeast species (e.g., Glaciozyma, Phenoliferia, Mrakia, and Vishniacozyma) were identified. It is concluded that the MALDI-TOF MS method can differentiate some closely related yeast species from polar regions, thus is suitable for the identification of polar yeasts.

Keywords: yeasts, Arctic, Antarctic, MALDI-TOF MS, identification

\section{INTRODUCTION}

The Arctic and Antarctica have always been the hotspot areas to study the diversity of coldadapted microorganisms, including yeasts (i.e., a versatile group of eukaryotic organisms; Buzzini et al., 2017). Polar yeasts can withstand the stress conditions in polar regions (e.g., low temperature, desiccation, low levels of nutrients, and UV irradiation), as they have evolved a set of structural and functional adaptation strategies to thrive in these extreme environments, such as production of cold-active enzymes, anti-freeze compounds, and extracellular polymers (Buzzini et al., 2012; Nizovoy et al., 2021). In recent years, it was found that polar yeasts with unique phenotypic characteristics had great biotechnological potentials, such as the production of cold-active enzymes 
(e.g., cellulase, amylase, protease, and lipase; Barahona et al., 2016; Tsuji, 2017; Wang et al., 2019) and bioactive compounds (e.g., exopolysaccharide; Pavlova et al., 2009; Viñarta et al., 2020), degradation of pollutant (e.g., phenol-related compounds and petroleum hydrocarbons) at low temperature (Fernandez et al., 2017; Martínez-Ávila et al., 2021), and potential probiotic (Coutinho et al., 2021a,b). Besides, some polar yeasts (e.g., Aureobasidium pullulans) may cause opportunistic infections and become potential pathogens to humans (Buzzini et al., 2017).

The traditional yeast identifications based on morphological, physiological, and biochemical characteristics are time-consuming and the conclusion may be unreliable due to lack of experience or subjective judgment (Agustini et al., 2014). The molecular method using the ribosomal DNA [internal transcribed spacer (ITS) and large subunit (LSU) gene regions] sequencing has been widely applied to polar yeast identification (Pathan et al., 2010; Zhang et al., 2014). In recent studies, multigene phylogenetic analyses based on DNA sequencing were used to identify novel yeast species isolated from various environments (Liu et al., 2015; Wang et al., 2015; Li et al., 2020). Although the molecular method is regarded as the gold standard in yeast identification, it is relatively time-consuming as compared to matrix-assisted laser desorption/ionization time-of-flight (MALDI-TOF) mass spectrometry (MS) analysis (Moothoo-Padayachie et al., 2013; Paul et al., 2019). Therefore, rapid and accurate identification of yeasts is preferred, especially in clinical, agricultural, and industrial applications (Spitaels et al., 2015; Jin et al., 2020; Martins et al., 2020). The accuracy of the MALDI-TOF MS based microbial identification has been proven to be comparable to automated systems based on biochemical and other phenotypic tests (Florio et al., 2018). In addition, MALDI-TOF MS was effective for identifying yeast isolated from food (e.g., Candida and Debaryomyces species; Pavlovic et al., 2014), beverages (e.g., Saccharomyces species; Usbeck et al., 2014; Zhang et al., 2020), and clinical samples (e.g., Candida and Cryptococcus species; Tan et al., 2012; Patel, 2019; Pote et al., 2020).

Identification of polar yeast species is a challenge as the current MALDI-TOF MS database of yeast species is limited that spectra profiles of polar yeast species are not included, leading to their misidentification as related species. To the best of our knowledge, there was only one study on the identification of psychrophilic yeast using MALDI-TOF MS, i.e., Dalluge et al. (2019) employed MALDI-TOF MS to rapidly characterize and distinguish three psychrophilic yeasts (Rhodotorula mucilaginosa, Naganishia vishniacii, and Dioszegia cryoxerica) from three mesophilic yeasts (Saccharomyces cerevisiae strain WLP862, S. cerevisiae strain WLP051, and S. pastorianus). The present study aimed to (1) construct a supplementary database with spectra of the 33 polar yeast species, (2) compare molecular analysis and MALDI-TOF MS analysis for yeast species differentiation, (3) compare ethanol-formic acid extraction method and on-plate

Abbreviations: MALDI-TOF MS, Matrix-assisted laser desorption/ionization timeof-flight mass spectrometry; MSPs, Main spectra profiles; LSU, Large subunit; ITS, Internal transcribed spacer; PCR, Polymerase chain reaction; AIC, Akaike information criteria; YMA, Yeast malt agar; CPCC, China Pharmaceutical Culture Collection; ML, Maximum Likelihood. extraction method for MALDI-TOF MS identification, and (4) determine the peptide markers of polar yeasts.

\section{MATERIALS AND METHODS}

\section{Yeast Strains}

A total of 33 yeast species were isolated from various environments in the Arctic and Antarctica (Table 1). Among them, 22 yeast species were isolated from the Ny-Alesund Region $\left(78^{\circ} 55^{\prime} \mathrm{N}, 11^{\circ} 56^{\prime} \mathrm{E}\right)$ located in the Svalbard Islands (high Arctic), and 11 species were isolated from the King George Island $\left(62^{\circ} 23^{\prime} \mathrm{S}, 58^{\circ} 27^{\prime} \mathrm{W}\right)$ located in the South Shetland Islands (maritime Antarctica). All the yeast strains were deposited in the China Pharmaceutical Culture Collection (CPCC), ${ }^{1}$ Institute of Medicinal Biotechnology, Chinese Academy of Medical Sciences \& Peking Union Medical College.

\section{DNA Extraction, Amplification, and Sequencing}

Genomic DNA of yeasts was extracted with a modified Chelex100 boiling method (Walsh et al., 1991). The yeast colony was placed into a $1.5 \mathrm{ml}$ centrifuge tube containing $100 \mu$ l Chelex 100 resin solution $[10 \%(\mathrm{wt} / \mathrm{vol})$ in water; Bio-Rad Laboratories, United States]. The mixture was vortexed and heated in a microwave oven for $4 \mathrm{~min}$. After centrifuging at $13,000 \mathrm{rpm}$ for $4 \mathrm{~min}$, the supernatant was used for the subsequent PCR amplification. The D1/D2 domains of the LSU ribosomal DNA and the ITS region of the ribosomal DNA were amplified with the target primers NL1 (5'-GCATATCAATAAGCGGA GGAAAAG-3') and NL4 (5'-GGTCCGTGTTTCAAGACGG-3'; Kurtzman and Robnett, 1991), ITS1F (5'-CTTGGTCATTTAG AGGAAGTAA-3'; Gardes and Bruns, 1993) and ITS4 (5'-TCCTCCGCTTATTGATATGC-3'; White et al., 1990), respectively. The PCR mixture $(50 \mu \mathrm{l})$ : Easy Taq Buffer $6.0 \mu \mathrm{l}$, Easy Taq DNA Polymerase $1.5 \mu \mathrm{l}$, dNTP $4.0 \mu \mathrm{l}$, target primer pairs $1.5 \mu \mathrm{l}$ for each one, $\mathrm{ddH}_{2} \mathrm{O} 33.5 \mu \mathrm{l}$. Amplification of the $\mathrm{D} 1 / \mathrm{D} 2$ domain was performed as follows: $94^{\circ} \mathrm{C}$ for $6 \mathrm{~min}$, followed by $40 \mathrm{cycles}$ of $94^{\circ} \mathrm{C}$ for $1 \mathrm{~min}, 50^{\circ} \mathrm{C}$ for $1 \mathrm{~min}$, and $72^{\circ} \mathrm{C}$ for $1 \mathrm{~min}$, and concluded with a final elongation step at $72^{\circ} \mathrm{C}$ for $5 \mathrm{~min}$. The PCR amplification of ITS region was as follows: $95^{\circ} \mathrm{C}$ for $3 \mathrm{~min}$, followed by 37 cycles of $94^{\circ} \mathrm{C}$ for $30 \mathrm{~s}$, $52^{\circ} \mathrm{C}$ for $30 \mathrm{~s}$, and $72^{\circ} \mathrm{C}$ for $40 \mathrm{~s}$, and a final elongation step at $72^{\circ} \mathrm{C}$ for $10 \mathrm{~min}$. The sequence data of $\mathrm{D} 1 / \mathrm{D} 2$ domains were deposited in the GenBank database under the accession numbers MZ686226-MZ686249 and MZ686251-MZ686259, whereas sequence data of ITS region under the accession numbers MZ683224-MZ683247 and MZ683249-MZ683257.

\section{Molecular Identification and Phylogenetic Analysis}

The yeast species were identified based on sequence similarity (i.e., the percentage of nucleotide identity with reference sequences) and the phylogenetic position. For sequence similarity

${ }^{1}$ http://www.cpcc.ac.cn 
TABLE 1 | Information on the origins of the 33 polar yeast species and results of molecular identification and matrix-assisted laser desorption/ionization time-of-flight mass spectrometry (MALDI-TOF MS)-based identification.

\begin{tabular}{|c|c|c|c|c|c|}
\hline \multirow{2}{*}{ Test strains } & \multirow{2}{*}{$\begin{array}{l}\text { Geographical } \\
\text { origins }\end{array}$} & \multirow{2}{*}{$\begin{array}{l}\text { Environmental } \\
\text { origins }\end{array}$} & \multicolumn{2}{|c|}{ Molecular biology analysis closest type strain } & \multirow{2}{*}{$\begin{array}{l}\text { MALDI-TOF MS-based } \\
\text { identification (score A* } \\
\text { /score } \mathrm{B}^{\#} \text { ) }\end{array}$} \\
\hline & & & ID by LSU (similarity \%) & ID by ITS (similarity \%) & \\
\hline \multicolumn{6}{|c|}{ Saccharomycetes } \\
\hline CPCC 300416 & Arctic & Sea water & Candida davisiana (99.67\%) & Candida davisiana (99.26\%) & Candida davisiana (9.720/9.228) \\
\hline CPCC 300347 & Antarctic & Dung & Candida glaebosa (99.32\%) & Candida glaebosa (99.19\%) & Candida glaebosa (9.742/9.510) \\
\hline CPCC 300486 & Antarctic & Sea water & Galactomyces geotrichum (99.83\%) & $\begin{array}{l}\text { Galactomyces geotrichum } \\
(99.68 \%)\end{array}$ & $\begin{array}{l}\text { Galactomyces geotrichum } \\
(9.836 / 9.002)\end{array}$ \\
\hline CPCC 300461 & Antarctic & Sea water & Metschnikowia australis (99.59\%) & $\begin{array}{l}\text { Metschnikowia australis } \\
(99.15 \%)\end{array}$ & $\begin{array}{l}\text { Metschnikowia australis } \\
(9.585 / 9.028)\end{array}$ \\
\hline CPCC 300438 & Arctic & Sea water & Metschnikowia bicuspidata (99.61\%) & $\begin{array}{l}\text { Metschnikowia bicuspidata } \\
(97.74 \%)\end{array}$ & $\begin{array}{l}\text { Metschnikowia bicuspidata } \\
(9.268 / 9.035)\end{array}$ \\
\hline CPCC 300437 & Arctic & Sea water & Metschnikowia zobellii (100\%) & Metschnikowia zobellii (98.38\%) & $\begin{array}{l}\text { Metschnikowia zobellii } \\
(9.539 / 9.303)\end{array}$ \\
\hline \multicolumn{6}{|c|}{ Cystobasidiomycetes } \\
\hline CPCC 300370 & Arctic & Dung & Cystobasidium laryngis (100\%) & $\begin{array}{l}\text { Cystobasidium laryngis } \\
(99.45 \%)\end{array}$ & $\begin{array}{l}\text { Cystobasidium laryngis } \\
(9.612 / 9.426)\end{array}$ \\
\hline CPCC 300329 & Antarctic & Soil & Cystobasidium ongulense (99.84\%) & $\begin{array}{l}\text { Cystobasidium ongulense } \\
(99.30 \%)\end{array}$ & $\begin{array}{l}\text { Cystobasidium ongulense } \\
(9.731 / 9.096)\end{array}$ \\
\hline \multicolumn{6}{|c|}{ Microbotryomycetes } \\
\hline CPCC 300487 & Antarctic & Soil & Glaciozyma antarctica (100\%) & Glaciozyma antarctica (99.89\%) & $\begin{array}{l}\text { Glaciozyma antarctica } \\
(9.788 / 9.515)\end{array}$ \\
\hline CPCC 300440 & Arctic & Sea water & Glaciozyma litoralis (100\%) & Glaciozyma litoralis (99.75\%) & Glaciozyma litoralis (9.707/9.562) \\
\hline CPCC 300358 & Antarctic & Soil & Glaciozyma martinii (100\%) & Glaciozyma martinii (100\%) & Glaciozyma martinii (9.692/9.559) \\
\hline CPCC 300392 & Arctic & Soil & Glaciozyma watsonii (100\%) & Glaciozyma watsonii (99.67\%) & Glaciozyma watsonii (9.802/9.447) \\
\hline CPCC 300366 & Arctic & Plant & Leucosporidium muscorum (100\%) & $\begin{array}{l}\text { Leucosporidium muscorum } \\
(98.93 \%)\end{array}$ & $\begin{array}{l}\text { Leucosporidium muscorum } \\
(9.209 / 6.283)\end{array}$ \\
\hline CPCC 300410 & Arctic & Plant & Leucosporidium scottii (100\%) & $\begin{array}{l}\text { Leucosporidium scottii } \\
(99.84 \%)\end{array}$ & $\begin{array}{l}\text { Leucosporidium scottii } \\
(9.484 / 9.283)\end{array}$ \\
\hline CPCC 300463 & Antarctic & Soil & Phenoliferia glacialis (100\%) & Phenoliferia glacialis (99.34\%) & Phenoliferia glacialis (9.676/9.107) \\
\hline CPCC 300464 & Antarctic & Soil & $\begin{array}{l}\text { Phenoliferia psychrophenolica } \\
(99.83 \%)\end{array}$ & $\begin{array}{l}\text { Phenoliferia psychrophenolica } \\
(99.32 \%)\end{array}$ & $\begin{array}{l}\text { Phenoliferia psychrophenolica } \\
(9.710 / 9.552)\end{array}$ \\
\hline CPCC 300465 & Antarctic & Soil & Phenoliferia psychrophila (99.68\%) & $\begin{array}{l}\text { Phenoliferia psychrophila } \\
(99.67 \%)\end{array}$ & $\begin{array}{l}\text { Phenoliferia psychrophila } \\
(9.241 / 6.232)\end{array}$ \\
\hline \multicolumn{6}{|c|}{ Tremellomycetes } \\
\hline CPCC 300411 & Arctic & Dung & $\begin{array}{l}\text { Cystofilobasidium macerans } \\
\text { (99.69\%) }\end{array}$ & $\begin{array}{l}\text { Cystofilobasidium macerans } \\
(99.68 \%)\end{array}$ & $\begin{array}{l}\text { Cystofilobasidium macerans } \\
(9.777 / 9.555)\end{array}$ \\
\hline CPCC 300426 & Antarctic & Lichen & Dioszegia hungarica (99.36\%) & Dioszegia hungarica (99.19\%) & Dioszegia hungarica (9.609/9.548) \\
\hline CPCC 300381 & Arctic & Feather & Filobasidium magnum (99.53\%) & Filobasidium magnum (99.82\%) & $\begin{array}{l}\text { Filobasidium magnum } \\
(9.703 / 8.483)\end{array}$ \\
\hline CPCC 300369 & Arctic & Dung & Goffeauzyma gastrica (100\%) & Goffeauzyma gastrica (99.68\%) & Goffeauzyma gastrica (9.621/9.515) \\
\hline CPCC 300368 & Arctic & Fresh water & Holtermanniella nyarrowii (99.52\%) & $\begin{array}{l}\text { Holtermanniella nyarrowii } \\
(99.48 \%)\end{array}$ & $\begin{array}{l}\text { Holtermanniella nyarrowii } \\
(9.624 / 9.534)\end{array}$ \\
\hline CPCC 300345 & Arctic & Plant & Mrakia aquatica (100\%) & Mrakia aquatica (98.75\%) & Mrakia aquatica (9.722/9.585) \\
\hline CPCC 300333 & Antarctic & Lichen & Mrakia blollopis (99.68\%) & Mrakia blollopis (98.89\%) & Mrakia blollopis (9.701/9.590) \\
\hline CPCC 300344 & Arctic & Plant & Mrakia niccombsii (100\%) & Mrakia niccombsii (100\%) & Mrakia niccombsii (9.528/9.531) \\
\hline CPCC 300477 & Arctic & Soil & Mrakia robertii (99.84\%) & Mrakia robertii (99.36\%) & Mrakia robertii (9.590/9.412) \\
\hline CPCC 300377 & Arctic & Feather & Naganishia albidosimilis (99.83\%) & Naganishia albidosimilis (100\%) & $\begin{array}{l}\text { Naganishia albidosimilis } \\
(9.734 / 5.059)\end{array}$ \\
\hline CPCC 300436 & Arctic & Sea water & Naganishia diffluens (99.84\%) & Naganishia diffluens (100\%) & Naganishia diffluens (9.681/9.063) \\
\hline CPCC 300475 & Arctic & Sea water & Naganishia friedmannii (99.68\%) & $\begin{array}{l}\text { Naganishia friedmannii } \\
(99.34 \%)\end{array}$ & $\begin{array}{l}\text { Naganishia friedmannii } \\
(9.510 / 9.120)\end{array}$ \\
\hline CPCC 300478 & Arctic & Soil & Piskurozyma fildesensis (99.84\%) & $\begin{array}{l}\text { Piskurozyma fildesensis } \\
(99.84 \%)\end{array}$ & $\begin{array}{l}\text { Piskurozyma fildesensis } \\
(9.563 / 9.291)\end{array}$ \\
\hline CPCC 300372 & Arctic & Fresh water & Vishniacozyma carnescens (99.20\%) & $\begin{array}{l}\text { Vishniacozyma carnescens } \\
(99.63 \%)\end{array}$ & $\begin{array}{l}\text { Vishniacozyma carnescens } \\
(9.606 / 9.320)\end{array}$ \\
\hline CPCC 300352 & Arctic & Plant & Vishniacozyma tephrensis (99.67\%) & $\begin{array}{l}\text { Vishniacozyma tephrensis } \\
(100 \%)\end{array}$ & $\begin{array}{l}\text { Vishniacozyma tephrensis } \\
(9.600 / 9.208)\end{array}$ \\
\hline CPCC 300476 & Arctic & Feather & Vishniacozyma victoriae (100\%) & Vishniacozyma victoriae (100\%) & $\begin{array}{l}\text { Vishniacozyma victoriae } \\
(9.720 / 9.453)\end{array}$ \\
\hline
\end{tabular}

*Score A: identification score using ethanol-formic acid extraction method.

"Score B: identification score using on-plate extraction method. 
determination, blastn searches were performed in the GenBank public sequence databases to find the closest related species.

For phylogenetic analysis, the sequences of D1/D2 domain and ITS region were aligned using $\mathrm{MAFFT}^{2}$ respectively. Some ambiguous sites were manually inspected in BioEdit version 7.0.9.0. ModelFinder of PhyloSuite version 1.1.16 was used to select the best-fit model $(\mathrm{GTR}+\mathrm{G}+\mathrm{I})$ using Akaike information criteria (AIC) for DNA substitution (Kalyaanamoorthy et al., 2017). A total of 1,072 characters (including gaps) were obtained. Maximum likelihood (ML) analysis was conducted by RAxML-HPC version 8.2.10 with 1,000 bootstrap replicates (Stamatakis, 2014). The phylogenetic tree was visualized and edited in FigTree version 1.4.4 (Rambaut, 2018), and bootstrap values $\geq 50 \%$ are shown above branches.

\section{Construction of MALDI-TOF MS Supplementary Database}

All the 33 yeast species were cultured on yeast malt agar (YMA; Difco, Becton-Dickinson, United States) at $12^{\circ} \mathrm{C}$ for 4-5 days. For supplementary database implementation, the main spectra profiles (MSPs) of each yeast species were created using three replicates of eight separated colonies from each yeast species to be included in the user-generated library.

Each yeast colony was extracted according to the ethanolformic acid extraction method. The yeast colony was placed into a $1.5 \mathrm{ml}$ centrifuge tube and mixed with $300 \mu \mathrm{l}$ of $\mathrm{ddH}_{2} \mathrm{O}$ and $900 \mu \mathrm{l}$ of absolute ethanol. The tubes were centrifuged at room temperature $(14,000 \mathrm{rpm}, 4 \mathrm{~min})$. After the supernatant was discarded, the obtained pellet was air-dried. Subsequently, $10 \mu \mathrm{l}$ of $70 \%$ formic acid (Lysis Solution 1, Autobio Diagnostics, China) and $10 \mu \mathrm{l}$ of acetonitrile (Lysis Solution 2, Autobio Diagnostics, China) were added and mixed entirely in the tubes. After centrifugation at $14,000 \mathrm{rpm}$ for $4 \mathrm{~min}$ at room temperature, $1.0 \mu \mathrm{l}$ of the supernatant was spotted in eight replicates onto a 96-spot polished steel target plate (Autobio Diagnostics, China) and air-dried at room temperature. Then, each spot was overlaid with $1.0 \mu \mathrm{l}$ of the matrix solution ( $\alpha$-cyano-4-hydroxycinnamic acid; Autobio Diagnostics, China) on each spot and air-dried completely before MALDI-TOF MS measurement.

Prior to MALDI-TOF MS analysis, the mass spectrometer was externally calibrated using calibrating agent (containing Escherichia coli DH5 $\alpha$, Ribonuclease, and Myoglobin; Autobio Diagnostics, China) with a protein mix of E.PM $3 \mathrm{~K}^{+}$ (3637.22 Da), E.PM $4 \mathrm{~K}^{+} \quad(4365.343 \mathrm{Da}), \quad$ E.PM $5 \mathrm{~K}^{+}$ $(5096.776 \mathrm{Da}), \quad$ E.PM $5.3 \mathrm{~K}^{+} \quad(5381.446 \mathrm{Da}), \quad$ E.PM $6 \mathrm{~K}^{+}$ $(6255.444 \mathrm{Da}), \quad$ E.PM $7 \mathrm{~K}^{+} \quad(7274.467 \mathrm{Da}), \quad$ E.PM $10 \mathrm{~K}^{+}$ $(10300.032 \mathrm{Da})$, E.PM $13 \mathrm{~K}^{+}(13683.173 \mathrm{Da})$, and E.PM $16 \mathrm{~K}^{+}$ (16952.232 Da). Spectra with peptide peaks outside the allowed average were not considered. Spectra profiles were loaded into the Autof Acquirer software Version 2.0.59 (Autobio Diagnostics, China). The MALDI-TOF MS spectra profile of each sample was measured by Autof ms1000 (Autobio Diagnostics, China). Spectral data were taken in the $\mathrm{m} / \mathrm{z}$

${ }^{2}$ https://mafft.cbrc.jp/alignment/server/ range of 2,000-20,000 Da. Pictures of sample-matrix crystals were taken by a built-in camera. The spectral data were collected by software Autof Acquirer version 2.0.59 (Autobio Diagnostics, China) and analyzed by software Autof Analyzer version 2.0.14 (Autobio Diagnostics, China).

The main spectra profiles of each yeast species were generated considering the 24 spectra profiles obtained and were saved in the reference library. This supplementary database of 33 polar yeast species can be found on CPCC, Institute of Medicinal Biotechnology, Chinese Academy of Medical Sciences \& Peking Union Medical College.

\section{MALDI-TOF MS Data Analysis}

The MALDI-TOF MS-based clustering analysis was performed using software Autof Analyzer version 2.0.14 (Autobio Diagnostics, China). MALDI mass spectra for individual yeast species from the 33 yeasts studied were collected and catalogued for comparison and identification of genus-specific peptide markers.

\section{Identification With Supplementary Database Using Two Extraction Methods}

The supplementary database was subsequently used for species identification using two extraction methods. All the 33 yeast species were cultured again on YMA (Difco, Becton-Dickinson, United States) at $12^{\circ} \mathrm{C}$ for $4-5$ days. Each yeast sample was extracted using both the ethanol-formic acid extraction method and the on-plate extraction method. For the on-plate extraction method, yeast colonies were directly transferred on the target plates as thin films using sterile inoculation loops. Following this, $1.0 \mu \mathrm{l}$ of Lysis Solution 1 (70\% formic acid) was mixed with the yeast sample on the plate by pipetting, and the resultant mixture was air-dried at room temperature. Finally, $1.0 \mu \mathrm{l}$ of the matrix solution was applied onto the spot and air-dried completely prior to MALDI-TOF MS measurement. After extraction procedures, all the yeast samples were identified by Autof ms1000, following the manufacturers' instructions.

For identification, the acquired spectrum was loaded into the Autof Acquirer version 2.0.59 (Autobio Diagnostics, China) and was compared with spectra deposited in the supplementary database as MSPs. The yeast samples were correctly identified to the species level required a score $>9.0$; a score between 6.0 and 9.0 indicated genus identification; but a score $<6.0$ indicated no significant similarity of the spectrum and unidentified.

\section{RESULTS AND DISCUSSION}

\section{Species Differentiation Using Molecular Analysis and MALDI-TOF MS Analysis}

A total of 33 yeast species were isolated from the Arctic (22 species) and Antarctic (11 species) and were used for sequence similarity analysis (Table 1) and phylogenetic analysis (Figure 1). These 33 yeast species belonged to 16 


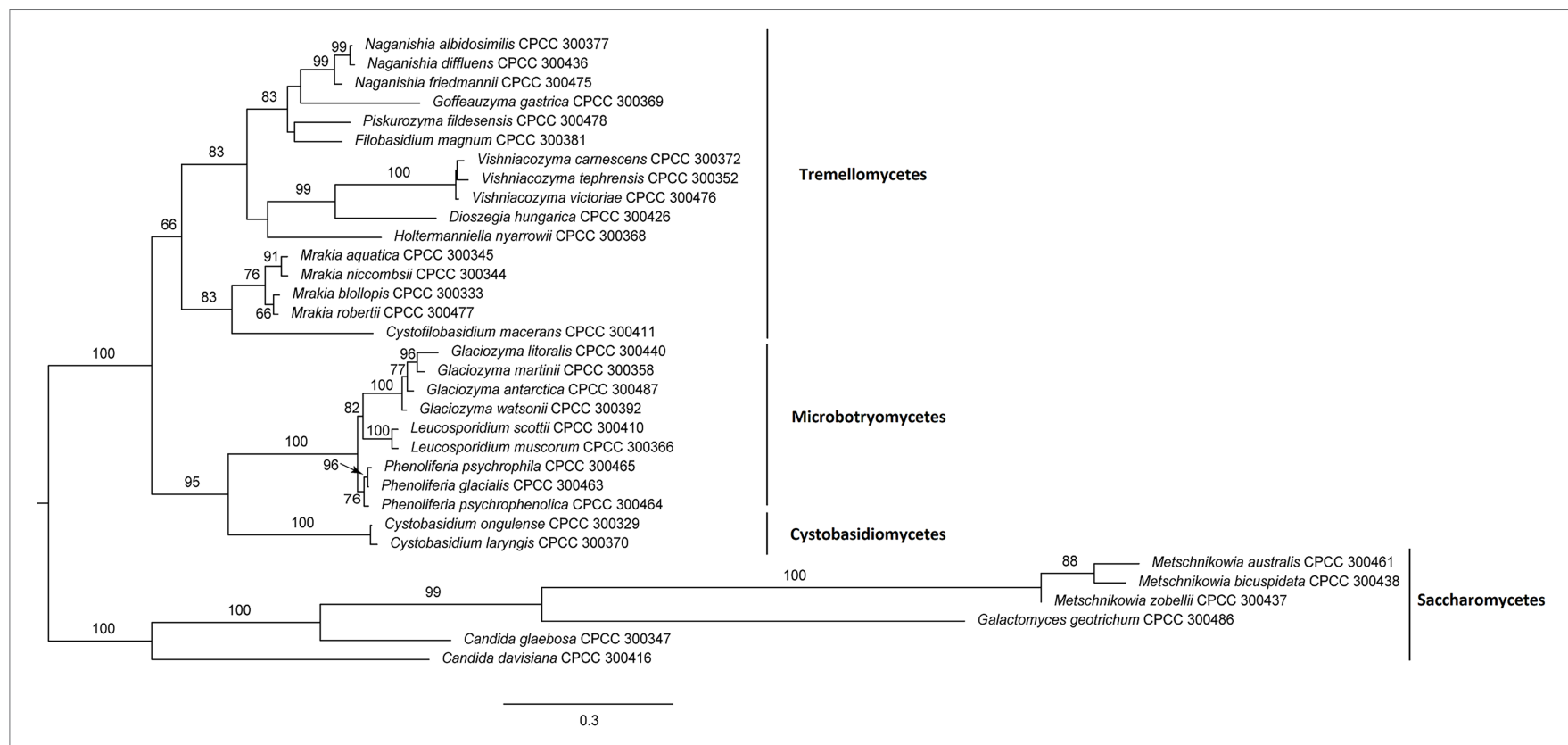

FIGURE 1 | Maximum likelihood (ML) tree inferred from sequences of D1/D2 domain and internal transcribed spacer (ITS) region under the GTR $+G+\mid$ model in RAXML. ML bootstrap values ( $\geq 50 \%$ ) are indicated along branches $(M L)$.

genera, 13 families, eight orders, four classes, and two phyla. In the present study, a ML phylogenetic tree was constructed using the combined sequences of the LSU rDNA gene and ITS region (Figure 1). The ML phylogenetic tree indicated that 27 yeast species belonged to the phylum Basidiomycota, and six yeast species belonged to the phylum Ascomycota. The Basidiomycota included three classes: Tremellomycetes (16 species), Microbotryomycetes (six species), and Cystobasidiomycetes (two species). The Ascomycota included one class: Saccharomycetes (six species). They were all supported by high bootstrap values $(\geq 50 \%)$ in the $\mathrm{ML}$ phylogenetic tree.

Based on previous molecular identification results, the MALDI-TOF MS supplementary database of the 33 yeast species was constructed based on the 24 spectra profiles for each species (e.g., Cystobasidium laryngis CPCC 300370 in Supplementary Figure S1). A hierarchical clustering dendrogram was generated using MSPs of yeast species in the supplementary database constructed (Figure 2). The topology of the clustering dendrogram was then compared with the phylogenetic tree based on sequencing data. The clustering of yeast species in dendrogram was basically consistent with phylogenetic analysis of DNA sequence data. For example, most yeast species (e.g., Glaciozyma, Mrakia, and Vishniacozyma) formed the expected groups in the two trees. However, Tremellomycetes, Microbotryomycetes, Cystobasidiomycetes, and Saccharomycetes clades formed the expected groups within the resulting phylogenetic tree but did not form groups in MALDI-TOF MS-based dendrogram. Wigmann et al. (2019) proposed that MALDI-TOF MS data was inappropriate for phylogenetic analysis, as it was based on the $\mathrm{m} / \mathrm{z}$ values of ribosomal proteins and other proteins but not protein sequences.

\section{Determination of Peptide Markers of Polar Yeast Species}

The mass spectra of the 33 polar yeasts were included as references in a supplementary MALDI-TOF MS database, and their colonial morphology were also recorded (Figure 3; Supplementary Figures S2, S3). The peptide peaks of all the 33 polar yeast species were compared in the present study, and 15 peptide peaks $(m / z$ deviation $\leq 10 \mathrm{Da})$ were detected in $\geq 9$ yeast species (Table 2 ). The common peptide peaks of polar yeast species were observed, such as $\mathrm{m} / z 2091.8$ and 2104.8 appeared in the four classes and $>70 \%$ polar yeast species. Furthermore, several peptide peaks $(m / z$ deviation $\leq 2 \mathrm{Da})$ were determined as certain genus-specific markers. For example, Glaciozyma-specific markers were $\mathrm{m} / z \quad 6160$ and 6799, Phenoliferia-specific marker $m / z 3019$ and 3709 (Table 3), Mrakia-specific marker $m / z$ 5966, Vishniacozyma-specific marker $\mathrm{m} / z 5006$ (Supplementary Table S1), and Metschnikowia-specific marker $m / z 5256$ (Supplementary Table S2). In addition, some peptide peaks in the same genus were not classified as a genusspecific marker (e.g., $m / z$ 3061.79-3064.02, $m / z$ 3673.92-3675.93, $\mathrm{m} / z$ 6082.18-6086.06, $\mathrm{m} / z$ 6123.42-6125.95, and $\mathrm{m} / \mathrm{z}$ 7346.557349.51 in Glaciozyma spp.), because their $\mathrm{m} / z$ deviations were above $2 \mathrm{Da}$ (Figure 3).

The majority of peptide markers for the 33 yeast species were in the range of $m / z 5000-8000$ (Table 2), indicating that proteins in this range were more stable and reproducible. Several peptide markers were determined in three psychrophilic yeasts (e.g., Naganishia-specific $\mathrm{m} / z$ 2980.15, Dioszegia-specific $\mathrm{m} / z$ 1106.6, and Rhodotorula-specific $m / z$ 1230.4; Dalluge et al., 2019). The $\mathrm{m} / \mathrm{z}$ value is only a simple characteristic of an individual protein, and many sequentially different proteins may produce similar $\mathrm{m} / \mathrm{z}$ values (Spinali et al., 2015). Therefore, the yeast-specific 


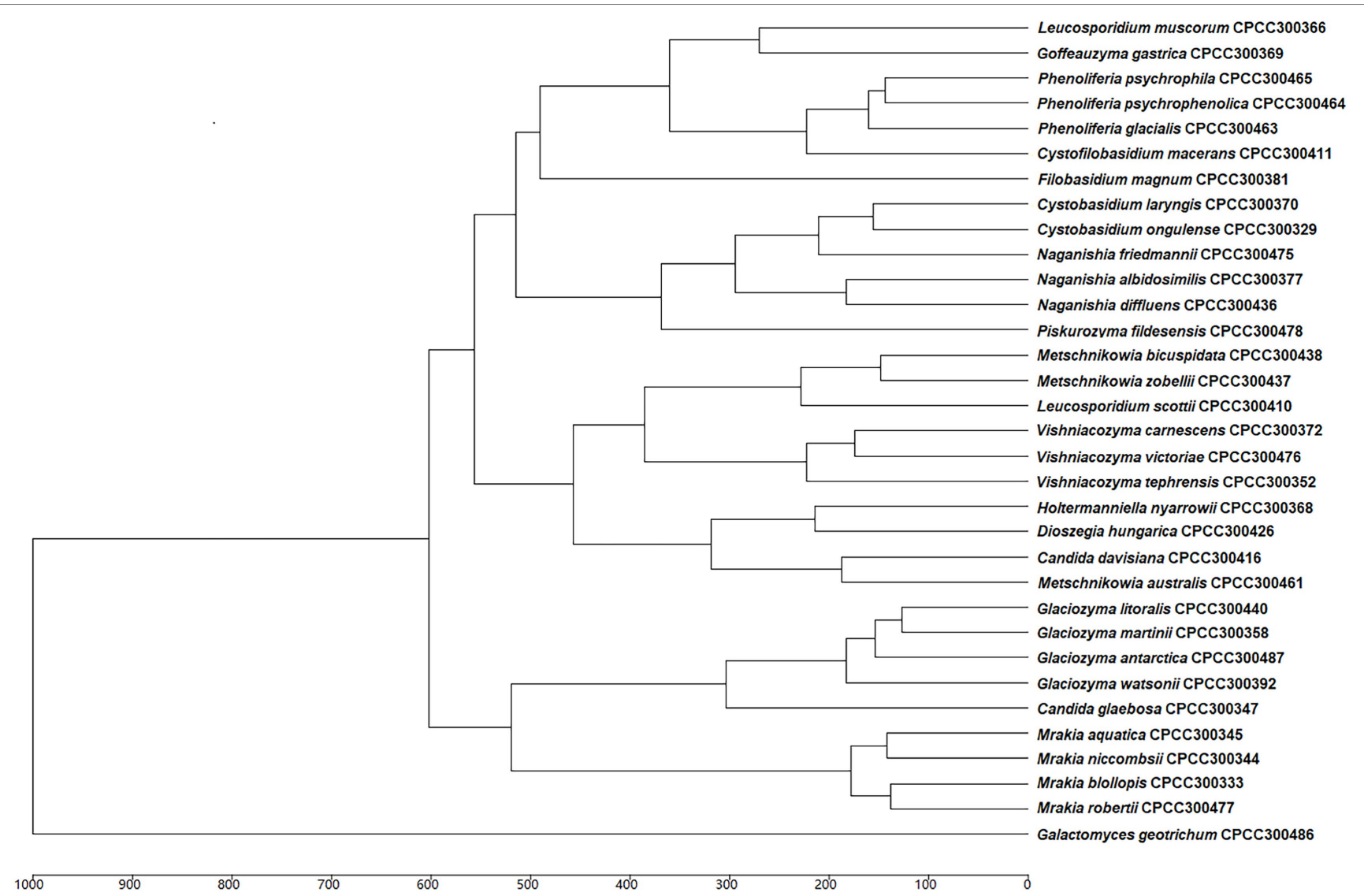

FIGURE 2 | Main spectra profile-based dendrogram of the 33 yeast species included in the supplementary database.

peptide markers detected by MALDI-TOF MS should be further analyzed by other methods (e.g., protein sequencing).

\section{Comparison of Ethanol-Formic Acid Extraction Method and On-Plate Extraction Method for MALDI-TOF MS-Based Identification}

The identification rate (\%) was defined as the number of correct species identifications represented in the supplementary database relative to the total number of tested yeast samples. The calculation revealed that 33 (score>9.0) out of the 33 yeast species in the supplementary database had an identification rate of $100 \%$, meaning that all yeast samples using the ethanolformic acid extraction method were correctly identified (Table 1). However, the identification rate was $87.88 \%$ (29 yeast species) using the on-plate extraction method in the present study (Table 1). Four yeast species were not identified to the species level using the on-plate extraction method, including Leucosporidium muscorum, Phenoliferia psychrophila, and Filobasidium magnum to genus level (score 6.0-9.0), and Naganishia albidosimilis to unidentified level (score <6.0). Based on the analysis of morphological characteristics, we found that these species were mucoid and glistening. Mucoid growth is usually related to the encapsulation of yeast cells from the production of extracellular polysaccharides (Kurtzman et al., 2011), which might protect yeast cells and result in insufficient extraction.

Several extraction methods were investigated to extract peptides from cell colonies prior to analysis by MALDI-TOF MS, including on-plate extraction method, ethanol-formic acid extraction method, and trifluoroacetic acid extraction method (Rahi et al., 2016). The highest quality mass spectra were acquired using the ethanol-formic acid extraction method in the present study. Ethanol is a lipid membrane solvent which can help cells to distribute into the growing crystal, release intercellular proteins, and avoid producing excess chemical noise for MALDI-TOF MS analysis (Madonna et al., 2000). The addition of formic acid can modify the $\mathrm{pH}$ of the matrix solvent and thereby increase the spectra quality in the range of $2-12 \mathrm{kDa}$ (Williams et al., 2003; Usbeck et al., 2013). In combination with the function of the above reagents, relatively high quality of MALDI-TOF MS data can be obtained. However, Wang et al. (2021) reported that the on-plate extraction method was more suitable and necessary for clinical identification, owing to its key advantages of simplicity and accuracy. These different effects of extraction methods on yeast identification may be partially due to the different species tested. 


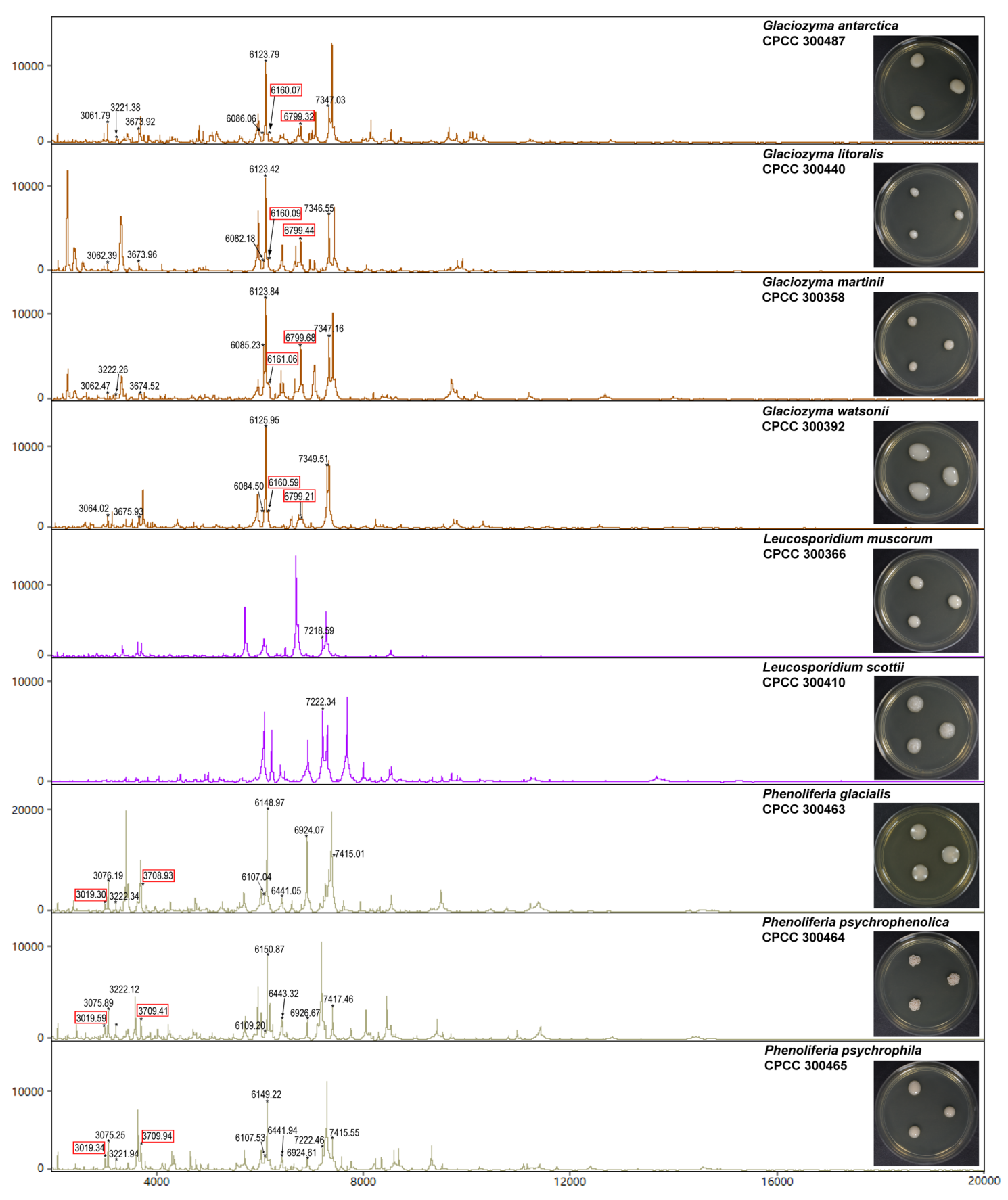

FIGURE 3 | Representative mass spectra of the nine yeast species in Microbotryomycetes. The Glaciozyma genus-specific markers (about $\mathrm{m} / \mathrm{z} 6160$ and $6799 \mathrm{Da}$ ) and Phenoliferia genus-specific markers (about $\mathrm{m} / \mathrm{z} 3019$ and $3709 \mathrm{Da}$ ) were indicated as the red quadrangles.

\section{CONCLUSION}

With the development of mass spectrometry technology, different biomolecules and biological systems can be studied directly (Jang and Kim, 2018). However, in comparison with the clinical microbes, the MALDI-TOF MS data for environmental microbes are limited, especially yeasts in the polar extreme environments. Hitherto, most investigations on yeasts in polar areas have remained limited to their biodiversity and the quantification of rare or new species (Buzzini et al., 2017). Therefore, it is necessary to establish a MALDI-TOF MS database for polar yeast identification.

In this study, MALDI-TOF MS is demonstrated to be a suitable and accurate technology for the rapid identification and differentiation of yeast species from the polar regions. 
TABLE 2 | Peptide markers of the 33 yeast species from polar regions.

\begin{tabular}{|c|c|c|c|c|c|c|c|c|c|c|c|c|c|c|c|}
\hline & 2091.8 & 2104.8 & 3074.4 & 3224.0 & 3976.5 & 4855.8 & 6029.0 & 6057.8 & 6086.2 & 6151.3 & 6406.6 & 6444.0 & 7346.2 & 7818.9 & 8542.3 \\
\hline Candida davisiana & + & + & -2.9 & & -1.6 & & + & + & & & + & + & -3.7 & +2.0 & \\
\hline Candida glaebosa & + & + & & & & +2.2 & +3.0 & & -2.1 & +2.2 & & & & & \\
\hline $\begin{array}{l}\text { Galactomyces } \\
\text { geotrichum }\end{array}$ & & & + & +1.5 & & & & & & & & & & & \\
\hline Metschnikowia australis & + & + & & & & & -2.4 & +1.6 & +3.0 & +1.2 & +1.4 & -3.6 & & -4.0 & \\
\hline $\begin{array}{l}\text { Metschnikowia } \\
\text { bicuspidata }\end{array}$ & & & & & & & +3.1 & & & & & & & & +2.6 \\
\hline Metschnikowia zobellii & + & + & + & & & & +3.1 & & & + & & & & +2.5 & \\
\hline Cystobasidium laryngis & + & + & -3.9 & & -2.1 & +3.5 & -3.6 & & & & & & -2.0 & & \\
\hline Cystobasidium ongulense & -1.2 & + & +2.5 & & & & & & & +2.9 & & +3.2 & & & \\
\hline Glaciozyma antarctica & + & + & & -2.6 & & & & & -4.1 & & & & + & & +1.5 \\
\hline Glaciozyma litoralis & & +4.3 & & & & & & & -3.9 & & & + & + & & \\
\hline Glaciozyma martinii & & & & -1.7 & & + & & & + & & & & + & & \\
\hline Glaciozyma watsonii & & & & & + & & & & -1.7 & & & & +3.3 & & \\
\hline $\begin{array}{l}\text { Leucosporidium } \\
\text { muscorum }\end{array}$ & + & + & & & & & + & & +4.6 & & & & & & -2.3 \\
\hline Leucosporidium scottii & & & & & & +1.1 & & & & & -1.1 & +1.3 & & +4.0 & \\
\hline Phenoliferia glacialis & +2.0 & +1.7 & +1.8 & -1.7 & +2.4 & & & & & -2.3 & & -3.0 & & & \\
\hline $\begin{array}{l}\text { Phenoliferia } \\
\text { psychrophenolica }\end{array}$ & + & + & +1.5 & -1.9 & + & -3.6 & & & & + & & + & & & + \\
\hline Phenoliferia psychrophila & + & + & + & -2.0 & & & & & & -2.1 & & -2.0 & + & & -2.2 \\
\hline $\begin{array}{l}\text { Cystofilobasidium } \\
\text { macerans }\end{array}$ & + & + & & + & +4.6 & -2.0 & -2.1 & +2.8 & & & & & & -3.7 & + \\
\hline Dioszegia hungarica & + & & -1.9 & +4.2 & +2.2 & -4.2 & & & & & & +3.4 & & + & \\
\hline Filobasidium magnum & + & -1.2 & & +3.1 & & -2.6 & & + & & & & & & & \\
\hline Goffeauzyma gastrica & + & + & & & +1.3 & +4.1 & -2.6 & + & & & & & & & \\
\hline Holtermanniella nyarrowii & & & & & & & & -1.6 & +3.0 & +2.6 & & & & & \\
\hline Mrakia aquatica & -2.4 & -2.2 & & & & + & & & & -3.6 & + & & & -1.8 & +1.2 \\
\hline Mrakia blollopis & -1.8 & -2.2 & & & + & & & & & & + & & & & \\
\hline Mrakia niccombsii & -2.1 & -1.4 & & -3.9 & & & & & & & + & + & & -1.9 & +1.1 \\
\hline Mrakia robertii & + & + & & & + & & & & & + & + & + & -1.6 & +1.7 & \\
\hline Naganishia albidosimilis & -1.6 & -4.3 & & +4.5 & -4.9 & & & & & & & & & & \\
\hline Naganishia diffluens & & & & & -3.0 & & & -1.9 & -1.9 & & & & & & + \\
\hline Naganishia friedmannii & + & +2.5 & +1.4 & & + & & & + & & & + & & +2.4 & & \\
\hline Piskurozyma fildesensis & + & + & & & & & + & & & & & & & & \\
\hline $\begin{array}{l}\text { Vishniacozyma } \\
\text { carnescens }\end{array}$ & +1.1 & + & & & + & & & +1.4 & +2.3 & & & & & +2.0 & \\
\hline Vishniacozyma tephrensis & & & & & & & + & -1.8 & + & & -1.9 & & + & & \\
\hline Vishniacozyma victoriae & +2.2 & +1.6 & & & & & & + & +1.3 & & & & + & -1.1 & \\
\hline
\end{tabular}

Peptide peaks appeared in $\geq 9$ yeast species were shown in the table $(\mathrm{m} / \mathrm{z}$ deviation $\leq 10 \mathrm{Da})$. + represent within a $\mathrm{m} / \mathrm{z}$ deviation range of $\pm 1 \mathrm{Da}$. 
TABLE 3 | Peptide markers of Glaciozyma, Leucosporidium, and Phenoliferia species in Microbotryomycetes.

\begin{tabular}{|c|c|c|c|c|c|c|c|c|}
\hline $\begin{array}{l}\text { Glaciozyma } \\
\text { antarctica }\end{array}$ & $\begin{array}{c}\text { Glaciozyma } \\
\text { litoralis }\end{array}$ & $\begin{array}{c}\text { Glaciozyma } \\
\text { martinii }\end{array}$ & $\begin{array}{c}\text { Glaciozyma } \\
\text { watsonii }\end{array}$ & $\begin{array}{l}\text { Leucosporidium } \\
\text { muscorum }\end{array}$ & $\begin{array}{l}\text { Leucosporidium } \\
\text { scottii }\end{array}$ & $\begin{array}{c}\text { Phenoliferia } \\
\text { glacialis }\end{array}$ & $\begin{array}{c}\text { Phenoliferia } \\
\text { psychrophenolica }\end{array}$ & $\begin{array}{l}\text { Phenoliferia } \\
\text { psychrophila }\end{array}$ \\
\hline 2092.47 & 2109.13 & 2293.27 & 3064.02 & 2091.19 & 7222.34 & 2093.77 & 2092.42 & 2092.31 \\
\hline 2104.64 & 2291.73 & 3062.47 & 3380.39 & 2104.71 & 8734.66 & 2106.54 & 2105.78 & 2105.08 \\
\hline 3061.79 & 3062.39 & 3222.26 & 3465.01 & 4269.44 & & 2294.39 & 2293.31 & 3019.34" \\
\hline 3221.38 & 3673.96 & 3377.06 & 3675.93 & 7218.59 & & 3019.30\# & $3019.59^{\#}$ & 3075.25 \\
\hline 3378.45 & 5981.46 & 3674.43 & 6084.50 & & & 3076.19 & 3075.89 & 3221.94 \\
\hline 3463.93 & 6108.28 & 5979.76 & 6125.95 & & & 3222.34 & 3222.12 & 3463.21 \\
\hline 3673.92 & 6082.18 & 6085.23 & 6160.59* & & & 3376.43 & 3376.88 & 3709.94\# \\
\hline 4271.97 & 6123.42 & 6123.84 & $6799.21 *$ & & & 3463.91 & 3463.84 & 4271.45 \\
\hline 5980.21 & 6160.09* & 6161.06* & 7349.51 & & & 3671.30 & $3709.41^{\#}$ & 6107.53 \\
\hline 6082.06 & 6799.44* & 6799.68* & 7775.31 & & & 3708.93\# & 4272.03 & 6149.22 \\
\hline 6123.79 & 7222.73 & 7347.16 & 8735.44 & & & 6107.04 & 6109.20 & 6441.97 \\
\hline $6160.07^{*}$ & 7346.55 & & & & & 6148.97 & 6150.87 & 6924.61 \\
\hline 6799.33* & 8734.66 & & & & & 6441.05 & 6443.32 & 7222.46 \\
\hline 7347.03 & & & & & & 6924.09 & 6926.67 & 7415.55 \\
\hline 7775.13 & & & & & & 7415.01 & 7417.46 & 7777.35 \\
\hline 8735.67 & & & & & & & 7774.92 & \\
\hline
\end{tabular}

Peptide peaks appeared in $\geq 3$ yeast species in Microbotryomycetes were shown in the table ( $\mathrm{m} / \mathrm{z}$ deviation $\leq 5 \mathrm{Da})$. *Glaciozyma genus-specific marker (m/z deviation $\leq 2$ Da). "Phenoliferia genus-specific marker ( $\mathrm{m} / \mathrm{z}$ deviation $\leq 2 \mathrm{Da}$ ).

We have established a supplementary database including 33 yeast species from the polar regions in the current study. Compared with the ethanol-formic acid extraction method, the on-plate extraction method is quicker and easier but with low accuracy. More than $70 \%$ of polar yeast species were observed the same peptide markers, such as $m / z 2091.8$ and 2104.8, and the majority of peptide markers for the 33 yeast species appeared in the range of $m / z$ 5000-8000. MALDI-TOF MS has potential application in microbial ecology studies, but standardized protocols and reference databases integration among laboratories is the main bottleneck at present (Lima et al., 2019). Therefore, these data are a foundation for the construction of a largescale database of yeast species from the polar regions and other environments in the future.

\section{DATA AVAILABILITY STATEMENT}

The datasets presented in this study can be found in online repositories. The names of the repository/repositories and accession number(s) can be found in the article/ Supplementary Material.

\section{REFERENCES}

Agustini, B. C., Silva, L. P., Bloch, C., Bonfim, T. M., and da Silva, G. A. (2014). Evaluation of MALDI-TOF mass spectrometry for identification of environmental yeasts and development of supplementary database. Appl. Microbiol. Biotechnol. 98, 5645-5654. doi: 10.1007/s00253-014-5686-7

Barahona, S., Yuivar, Y., Socias, G., Alcaíno, J., Cifuentes, V., and Baeza, M. (2016). Identification and characterization of yeasts isolated from sedimentary rocks of union glacier at the Antarctica. Extremophiles 20, 479-491. doi: 10.1007/s00792-016-0838-6

Buzzini, P., Branda, E., Goretti, M., and Turchetti, B. (2012). Psychrophilic yeasts from worldwide glacial habitats: diversity, adaptation strategies and biotechnological potential. FEMS Microbiol. Ecol. 82, 217-241. doi: 10.1111/j.1574-6941.2012.01348.x

\section{AUTHOR CONTRIBUTIONS}

TZ and LY designed the study. CH conducted labwork, data analysis, and wrote the manuscript. JF conducted parts of data analysis. JS preserved the yeast strains. TZ revised the manuscript. All authors contributed to the article and approved the submitted version.

\section{FUNDING}

This research was supported by National Natural Science Foundation of China (NSFC; Grant no. 31670025); CAMS Innovation Fund for Medical Sciences (Grant no. 2021-I2M1-055); Projects of the Chinese Arctic and Antarctic Administration, State Oceanic Administration; and National Microbial Resource Center (Grant no. NMRC-2021-3).

\section{SUPPLEMENTARY MATERIAL}

The Supplementary Material for this article can be found online at: https://www.frontiersin.org/articles/10.3389/fmicb.2022.832893/ full\#supplementary-material

Buzzini, P., Turk, M., Perini, L., Turchetti, B., and Gunde-Cimerman, N. (2017). "Yeasts in polar and subpolar habitats," in Yeasts in Natural Ecosystems: Diversity. eds. P. Buzzini, M. A. Lachance and A. Yurkov (Cham: Springer), 331-365.

Coutinho, J. O. P. A., Peixoto, T. S., de Menezes, G. C. A., Carvalho, C. R. Ogaki, M. B., Gomes, E. C. Q., et al. (2021a). In vitro and in vivo evaluation of the probiotic potential of Antarctic yeasts. Probiotics Antimicrob. Proteins 13, 1338-1354. doi: 10.1007/s12602-021-09758-8

Coutinho, J. O. P. A., Quintanilha, M. F., Campos, M. R. A., Ferreira, E., de Menezes, G. C. A., Rosa, L. H., et al. (2021b). Antarctic strain of Rhodotorula mucilaginosa UFMGCB 18, 377 attenuates mucositis induced by 5-fluorouracil in mice. Probiotics Antimicrob. Proteins. doi: 10.1007/ s12602-021-09817-0 [Epub ahead of print]

Dalluge, J. J., Brown, E. C., and Connell, L. B. (2019). Toward a rapid method for the study of biodiversity in cold environments: the characterization of 
psychrophilic yeasts by MALDI-TOF mass spectrometry. Extremophiles 23, 461-466. doi: 10.1007/s00792-019-01097-5

Fernandez, P. M., Martorell, M. M., Blaser, M. G., Ruberto, L. A. M., de Figueroa, L. I. C., and Mac Cormack, W. P. (2017). Phenol degradation and heavy metal tolerance of Antarctic yeasts. Extremophiles 21, 445-457. doi: 10.1007/s00792-017-0915-5

Florio, W., Tavanti, A., Barnini, S., Ghelardi, E., and Lupetti, A. (2018). Recent advances and ongoing challenges in the diagnosis of microbial infections by MALDI-TOF mass spectrometry. Front. Microbiol. 9:1097. doi: 10.3389/ fmicb.2018.01097

Gardes, M., and Bruns, T. D. (1993). ITS primers with enhanced specificity for basidiomycetes-application to identification of mycorrhizae and rusts. Mol. Ecol. 2, 113-118. doi: 10.1111/j.1365-294X.1993.tb00005.x

Jang, K. S., and Kim, Y. H. (2018). Rapid and robust MALDI-TOF MS techniques for microbial identification: a brief overview of their diverse applications. J. Microbiol. 56, 209-216. doi: 10.1007/s12275-018-7457-0

Jin, L., Cao, J. R., Xue, X. Y., Wu, H., Wang, L. F., Guo, L., et al. (2020). Clinical and microbiological characteristics of Cryptococcus gattii isolated from 7 hospitals in China. BMC Microbiol. 20:73. doi: 10.1186/s12866-02001752-4

Kalyaanamoorthy, S., Minh, B. Q., Wong, T. K. F., von Haeseler, A., and Jermiin, L. S. (2017). ModelFinder: fast model selection for accurate phylogenetic estimates. Nat. Methods 14, 587-589. doi: 10.1038/nmeth.4285

Kurtzman, C. P., Fell, J. W., Boekhout, T., and Robert, V. (2011). "Methods for isolation, phenotypic characterization and maintenance of yeasts," in The Yeasts: A Taxonomic Study. 5th Edn. eds. C. P. Kurtzman, J. W. Fell and T. Boekhout (Amsterdam: Elsevier), 88-107.

Kurtzman, C. P., and Robnett, C. J. (1991). Phylogenetic relation among species of Saccharomyces, Schizosaccharomyces, Debaryomyces and Schwanomyces determined from partial ribosomal RNA sequences. Yeast 7, 167-172. doi: 10.1002/yea. 320070107

Li, A. H., Yuan, F. X., Groenewald, M., Bensch, K., Yurkov, A. M., Li, K., et al. (2020). Diversity and phylogeny of basidiomycetous yeasts from plant leaves and soil: proposal of two new orders, three new families, eight new genera and one hundred and seven new species. Stud. Mycol. 96, 17-140. doi: 10.1016/j.simyco.2020.01.002

Lima, M. S., de Lucas, R. C., Lima, N., Polizeli, M. L. T. M., and Santos, C. (2019). Fungal community ecology using MALDI-TOF MS demands curated mass spectral databases. Front. Microbiol. 10:315. doi: 10.3389/fmicb.2019.00315

Liu, X. Z., Wang, Q. M., Theelen, B., Groenewald, M., Bai, F. Y., and Boekhout, T. (2015). Phylogeny of tremellomycetous yeasts and related dimorphic and filamentous basidiomycetes reconstructed from multiple gene sequence analyses. Stud. Mycol. 81, 1-26. doi: 10.1016/j.simyco.2015.08.001

Madonna, A. J., Basile, F., Ferrer, I., Meetani, M. A., Rees, J. C., and Voorhees, K. J. (2000). On-probe sample pretreatment for the detection of proteins above $15 \mathrm{KDa}$ from whole cell bacteria by matrix-assisted laser desorption/ionization time-of-flight mass spectrometry. Rapid Commun. Mass Spectrom. 14, 2220-2229. doi: 10.1002/1097-0231(20001215)14:23<2220::AID-RCM155>3.0. $\mathrm{CO} ; 2-4$

Martínez-Ávila, L., Peidro-Guzmán, H., Pérez-Llano, Y., Moreno-Perlín, T., Sánchez-Reyes, A., Aranda, E., et al. (2021). Tracking gene expression, metabolic profiles, and biochemical analysis in the halotolerant basidiomycetous yeast Rhodotorula mucilaginosa EXF-1630 during benzo[a]pyrene and phenanthrene biodegradation under hypersaline conditions. Environ. Pollut. 271:116358. doi: $10.1016 /$ j.envpol.2020.116358

Martins, P. M. M., Batista, N. N., Miguel, M., Simão, J. B. P., Soares, J. R., and Schwan, R. F. (2020). Coffee growing altitude influences the microbiota, chemical compounds and the quality of fermented coffees. Food Res. Int. 129:108872. doi: 10.1016/j.foodres.2019.108872

Moothoo-Padayachie, A., Kandappa, H. R., Krishna, S. B. N., Maier, T., and Govender, P. (2013). Biotyping Saccharomyces cerevisiae strains using matrixassisted laser desorption/ionization time-of-flight mass spectrometry (MALDITOF MS). Eur. Food Res. Technol. 236, 351-364. doi: 10.1007/s00217-012-1898-1

Nizovoy, P., Bellora, N., Haridas, S., Sun, H., Daum, C., Barry, K., et al. (2021). Unique genomic traits for cold adaptation in Naganishia vishniacii, a polyextremophile yeast isolated from Antarctica. FEMS Yeast Res. 21:foaa056. doi: 10.1093/femsyr/foaa056

Patel, R. (2019). A moldy application of MALDI: MALDI-ToF mass spectrometry for fungal identification. J. Fungi 5:4. doi: 10.3390/jof5010004
Pathan, A. A. K., Bhadra, B., Begum, Z., and Shivaji, S. (2010). Diversity of yeasts from puddles in the vicinity of midre lovénbreen glacier, arctic and bioprospecting for enzymes and fatty acids. Curr. Microbiol. 60, 307-314. doi: 10.1007/s00284-009-9543-3

Paul, S., Singh, P., Sharma, S., Prasad, G. S., Rudramurthy, S. M., Chakrabarti, A., et al. (2019). MALDI-TOF MS-based identification of melanized fungi is faster and reliable after the expansion of in-house database. Proteomics Clin. Appl. 13:e1800070. doi: 10.1002/prca.201800070

Pavlova, K., Panchev, I., Krachanova, M., and Gocheva, M. (2009). Production of an exopolysaccharide by Antarctic yeast. Folia Microbiol. 54, 343-348. doi: $10.1007 /$ s12223-009-0049-y

Pavlovic, M., Mewes, A., Maggipinto, M., Schmidt, W., Messelhäußer, U., Balsliemke, J., et al. (2014). MALDI-TOF MS based identification of foodborne yeast isolates. J. Microbiol. Methods 106, 123-128. doi: 10.1016/j. mimet.2014.08.021

Pote, S. T., Sonawane, M. S., Rahi, P., Shah, S. R., Shouche, Y. S., Patole, M. S., et al. (2020). Distribution of pathogenic yeasts in different clinical samples: their identification, antifungal susceptibility pattern, and cell invasion assays. Infect Drug Resist. 13, 1133-1145. doi: 10.2147/IDR.S238002

Rahi, P., Prakash, O., and Shouche, Y. S. (2016). Matrix-assisted laser desorption/ ionization time-of-flight mass-spectrometry (MALDI-TOF MS) based microbial identifications: challenges and scopes for microbial ecologists. Front. Microbiol. 7:1359. doi: $10.3389 /$ fmicb.2016.01359

Rambaut, A. (2018). Figtree version 1.4.4. Available at: https://github.com/ rambaut/figtree (Accessed November 26, 2018).

Spinali, S., van Belkum, A., Goering, R. V., Girard, V., Welker, M., Van Nuenen, M., et al. (2015). Microbial typing by matrix-assisted laser desorption ionization-time of flight mass spectrometry: do we need guidance for data interpretation? J. Clin. Microbiol. 53, 760-765. doi: 10.1128/ JCM.01635-14

Spitaels, F., Wieme, A. D., Janssens, M., Aerts, M., Van Landschoot, A., De Vuyst, L., et al. (2015). The microbial diversity of an industrially produced lambic beer shares members of a traditionally produced one and reveals a core microbiota for lambic beer fermentation. Food Microbiol. 49, 23-32. doi: $10.1016 /$ j.fm.2015.01.008

Stamatakis, A. (2014). RAxML version 8: a tool for phylogenetic analysis and post-analysis of large phylogenies. Bioinformatics 30, 1312-1313. doi: 10.1093/ bioinformatics/btu033

Tan, K. E., Ellis, B. C., Lee, R., Stamper, P. D., Zhang, S. X., and Carroll, K. C. (2012). Prospective evaluation of a matrix-assisted laser desorption ionizationtime of flight mass spectrometry system in a hospital clinical microbiology laboratory for identification of bacteria and yeasts: a bench-by-bench study for assessing the impact on time to identification and cost-effectiveness. J. Clin. Microbiol. 50, 3301-3308. doi: 10.1128/JCM.01405-12

Tsuji, M. (2017). Genetic diversity of yeasts from East Ongul Island, East Antarctica and their extracellular enzymes secretion. Polar Biol. 41, 249-258. doi: 10.1007/s00300-017-2185-1

Usbeck, J. C., Kern, C. C., Vogel, R. F., and Behr, J. (2013). Optimization of experimental and modelling parameters for the differentiation of beverage spoiling yeasts by matrix-assisted-laser-desorption/ionizationtime-of-flight mass spectrometry (MALDI-TOF MS) in response to varying growth conditions. Food Microbiol. 36, 379-387. doi: 10.1016/j. fm.2013.07.004

Usbeck, J. C., Wilde, C., Bertrand, D., Behr, J., and Vogel, R. F. (2014). Wine yeast typing by MALDI-TOF MS. Appl. Microbiol. Biotechnol. 98, 3737-3752. doi: 10.1007/s00253-014-5586-x

Viñarta, S. C., Angelicola, M. V., Van Nieuwenhove, C., Aybar, M. J., and de Figueroa, L. I. C. (2020). Fatty acids profiles and estimation of the biodiesel quality parameters from Rhodotorula spp. from Antarctica. Biotechnol. Lett. 42, 757-772. doi: 10.1007/s10529-020-02796-2

Walsh, P. S., Metzger, D. A., and Higuchi, R. (1991). Chelex 100 as a medium for simple extraction of DNA for PCR-based typing from forensic material. Biotechniques 10, 506-513. doi: 10.2144/000114018

Wang, Q. M., Begerow, D., Groenewald, M., Liu, X. Z., Theelen, B., Bai, F. Y., et al. (2015). Multigene phylogeny and taxonomic revision of yeasts and related fungi in the Ustilaginomycotina. Stud. Mycol. 81, 55-83. doi: 10.1016/j. simyco.2015.10.004

Wang, Y., Le, L. T. H. L., Yoo, W., Lee, C. W., Kim, K. K., Lee, J. H., et al. (2019). Characterization, immobilization, and mutagenesis of a novel cold- 
active acetylesterase (EaAcE) from Exiguobacterium antarcticum B7. Int. J. Biol. Macromol. 136, 1042-1051. doi: 10.1016/j.ijbiomac.2019.06.108

Wang, J., Wang, H., Cai, K., Yu, P., Liu, Y., Zhao, G., et al. (2021). Evaluation of three sample preparation methods for the identification of clinical strains by using two MALDI-TOF MS systems. J. Mass Spectrom. 56:e4696. doi: 10.1002/jms.4696

White, T. J., Bruns, T., Lee, S. J. W. T., and Taylor, J. L. (1990). "Amplification and direct sequencing of fungal ribosomal RNA genes for phylogenetics," in PCR Protocols: a guide to methods and applications. eds. M. A. Innis, D. H. Gelfand, J. J. Sninsky and T. J. White (New York: Academic Press), 315-322.

Wigmann, É. F., Behr, J., Vogel, R. F., and Niessen, L. (2019). MALDI-TOF MS fingerprinting for identification and differentiation of species within the Fusarium fujikuroi species complex. Appl. Microbiol. Biotechnol. 103, 5323-5337. doi: 10.1007/s00253-019-09794-z

Williams, T. L., Andrzejewski, D., Lay, J. O., and Musser, S. M. (2003). Experimental factors affecting the quality and reproducibility of MALDI TOF mass spectra obtained from whole bacteria cells. J. Am. Soc. Mass Spectrom. 14, 342-351. doi: 10.1016/S1044-0305(03)00065-5

Zhang, J., Plowman, J. E., Tian, B., Clerens, S., and On, S. L. W. (2020). An improved method for MALDI-TOF analysis of wine-associated yeasts. J. Microbiol. Methods 172:105904. doi: 10.1016/j.mimet.2020.105904
Zhang, T., Zhang, Y. Q., Liu, H. Y., Su, J., Zhao, L. X., and Yu, L. Y. (2014). Cryptococcus fildesensis sp. nov., a psychrophilic basidiomycetous yeast isolated from Antarctic moss. Int. J. Syst. Evol. Microbiol. 64, 675-679. doi: 10.1099/ ijs.0.054981-0

Conflict of Interest: The authors declare that the research was conducted in the absence of any commercial or financial relationships that could be construed as a potential conflict of interest.

Publisher's Note: All claims expressed in this article are solely those of the authors and do not necessarily represent those of their affiliated organizations, or those of the publisher, the editors and the reviewers. Any product that may be evaluated in this article, or claim that may be made by its manufacturer, is not guaranteed or endorsed by the publisher.

Copyright (C) $2022 \mathrm{He}$, Feng, Su, Zhang and Yu. This is an open-access article distributed under the terms of the Creative Commons Attribution License (CC BY). The use, distribution or reproduction in other forums is permitted, provided the original author(s) and the copyright owner(s) are credited and that the original publication in this journal is cited, in accordance with accepted academic practice. No use, distribution or reproduction is permitted which does not comply with these terms. 